\title{
ANALISIS KEMAMPUAN SALURAN DRAINASE TERHADAP GENANGAN BANJIR DI JALAN GUNUNG BUNGKUK KOTA BENGKULU DENGAN MENGGUNAKAN APLIKASI EPA SWMM 5.1
}

\author{
Hendy Apriyanza ${ }^{1)}$, Khairul Amri' ${ }^{2}$, Gusta Gunawan ${ }^{3)}$ \\ ${ }^{122) 3)}$ Program Studi Teknik Sipil, Fakultas Teknik UNIB, Jl. W. R. Supratman, \\ Kandang Limun, Bengkulu 38371, Telp. (0736)344087 \\ e-mail: hendyapriyanza06gmail.com
}

\begin{abstract}
This study aims to determine the flood discharge plan, discharge the existing channel and analyze the condition of the existing channel and look for alternatives to handling flood inundation at the location of flood inundation. Retrieval of data by measuring the existing channel in the flood inundation location. Calculation of peak discharge uses rational methods for various times of plan return. Rainfall calculation results of the plan that meets the requirements are type 1 Gumbel Method. The results of the research and calculations are known that the amount of existing channel discharge in seven locations of flood inundation ie left and right Mountain Bambat Road is $0.934 \mathrm{m3} / \mathrm{sec}$ and $3.798 \mathrm{~m} 3 / \mathrm{sec} .2,261 \mathrm{~m} 3 / \mathrm{sec}$, the left and right Gunung Bungkuk Roads are $0.134 \mathrm{m3} / \mathrm{sec}$ and $0.164 \mathrm{~m} 3 / \mathrm{sec}$ while the flood discharge is $1.897 \mathrm{~m} 3$ / sec, Gunung Bungkuk 1 Road is $0.30 \mathrm{~m} 3 / \mathrm{sec}$ while the flood discharge is $0.471 \mathrm{~m} 3$ / sec, Gunung Bungkuk Road 4 hunchback of $0.190 \mathrm{~m} 3 / \mathrm{sec}$ while the flood discharge is 1,336 m3 / sec and Gunung Bungkuk Road is 4 0,173 m3 / sec while the flood discharge is 0,864 m3 / sec and for the drainage of Jalan Gunung Bungkuk is not calculated the channel discharge is due to the channel being closed so that the channel dimension not obtained but for the flood discharge of $2.230 \mathrm{~m} 3 / \mathrm{sec}$ and $0.447 \mathrm{~m} 3 / \mathrm{sec}$. Thus, it shows that the existing discharge channel on the existing Gunung Bungkuk Hump Mountain Road is unable to accommodate the planned flood discharge. The alternative to flood inundation is by re-planning drainage channels, channel normalization activities, and improving coordination between the government and the community in maintaining drainage channels.
\end{abstract}

Keywords: flood, the flood discharge plan, the existing channel discharge

\section{PENDAHULUAN}

Banjir hal yang tidak asing lagi di Indonesia, khususnya pada musim hujan, mengingat hampir semua kota di Indonesia mengalami bencana banjir. Peristiwa banjir pada umumnya merupakan interaksi dari kejadian alam dan pengaruh perbuatan manusia, merupakan sebuah dilema yang pada umumnya sulit dipecahkan dan cenderung semakin meningkat, sejalan dengan tingkat perkembangan masyarakat. Untuk mengurangi kerugian-kerugian yang ditimbulkan oleh banjir diperlukan tindakan- tindakan penanganan banjir baik yang bersifat phisik karena bersifat memperbaiki alam dan tindakan yang bersifat non phisik karena bersifat pencegahan terjadinya kerugian atau bencana (Purbawijaya, 2011).

Genangan banjir akibat air hujan atau air kiriman yang terkonsentrasi disuatu tempat dan tidak dapat mengalir pada saluran drainase dalam jangka waktu berjam-jam hingga berhari-hari. Genangan banjir yang diakibatkan oleh beberapa faktor yaitu curah hujan yang tinggi, saluran drainase yang rusak, saluran yang tidak mampu lagi 
memuat aliran air hujan sehingga genangan banjir ini menjadi masalah saat mengenai pemukiman dan persawahan.

Drainase merupakan sebuah sistem yang dibuat untuk menangani persoalan kelebihan air yang berada di atas permukaan tanah maupun air yang berada di bawah permukaan tanah. Kelebihan air dapat disebabkan oleh intensitas hujan yang tinggi atau akibat durasi hujan yang lama (Wesli, 2008).

Jalan Gunung Bungkuk Baru merupakan kelurahan yang berada di wilayah Kelurahan Tanah Patah. Pembangunan gedung-gedung dan pertokoan di wilayah Jalan Gunung Bungkuk telah mengakibatkan berkurangnya luas area resapan air hujan dengan cepat dan menimbulkan genangan banjir. Kebiasaan buruk membuang sampah di saluran drainase membuat air meluap dari saluran sehingga menimbulkan genangan banjir setiap musim hujan. Saluran tersebut meluap karena kapasitasnya lebih kecil dari debit limpasan yang masuk ke dalamnya dan elevasi saluran yang cukup landai.

Desain saluran yang cocok untuk mengatasinya adalah perbaikan dimensi saluran yaitu dengan menambah kedalaman saluran, lebar saluran, atau kombinasi keduanya.(Luthfi dkk, 2017).

Alternatif penanggulangan genangan banjir adalah dengan melakukan perencanaan ulang saluran drainase, kegiatan normalisasi saluran, serta meningkatkan koordinasi antara pemerintah dan masyarakat dalam memelihara saluran drainase (Ardiansyah,dkk 2017 ).

Permasalahan banjir dan genangan menimbulkan kerugian pada masyarakat di jalan Gunung Bungkuk. Apabila hal ini dibiarkan terus menerus maka akan menciptakan ketidaknyamanan kepada warga serta dapat menimbulkan kerugian materil, masalah sosial dan ekonomi.

\section{Siklus hidrologi}

Siklus hidrologi atau daur hidrologi adalah gerakan air laut ke udara, kemudian jatuh ke permukaan tanah dan akhirnya kembali mengalir ke laut. Siklus hidrologi adalah proses yang diawali oleh evaporasi atau penguapan kemudian terjadinya kondensasi dari awan hasil evaporasi. Awan terus terproses, sehingga terjadi salju dan atau hujan yang jatuh kepermukaan tanah. Pada muka tanah air hujan ada yang mengalir di permukaan tanah, sebagai air run off dan sebagian infiltrasi atau meresap kedalam lapisan tanah.

\section{Drainase perkotaan}

Drainase merupakan salah satu fasilitas dasar yang dirancang sebagai sistem guna memenuhi kebutuhan masyarakat dan merupakan komponen penting dalam perencanaan kota khususnya perencanaan infrastruktur. Drainase berasal dari bahasa Inggris "drainage" yang mempunyai arti mengalirkan, menguras, membuang atau mengalirkan air. Drainase diartikan sebagai serangkaian bangunan air yang berfungsi untuk mengurangi membuang kelebihan air dari suatu kawasan atau lahan, sehingga lahan dapat difungsikan secara optimal,. Drainase juga diartikan sebagai usaha untuk mengontrol kualitas air tanah dalam kaitannya dengan salinitas. (Tigri dkk, 2013).

\section{Banjir}

Banjir adalah suatu kondisi dimana tidak tertampungnya air dalam saluran pembuangan (kali) atau bertambahnya aliran air di dalam saluran pembuangan. banjir merupakan peristiwa alam yang dapat menimbulkan kerugian harta benda penduduk serta dapat menimbulkan korban jiwa (Suripin, 2004). Menurut (Suroso, 2006), aliran atau genangan air ini dapat terjadi karena adanya luapan-luapan pada daerah dikanan dan kiri sungai akibat alur 
sungai tidak memiliki kapasitas yang cukup bagi debit aliran yang lewat.

\section{Analisa hujan}

\section{Metode distribusi normal}

Metode Log Normal apabila digambarkan pada kertas peluang logaritmik akan merupakan persamaan garis lurus, sehingga dapat dinyatakan sebagai model matematik dengan persamaan sebagai berikut (Soewarno, 1995):

$\log \mathrm{X}_{\mathrm{T}}=\log \overline{\mathrm{X}}+\mathrm{K}_{\mathrm{T}}$.

Sdlog $\bar{X}$

$$
\begin{aligned}
& \log \bar{X}=\frac{\sum_{=1}^{X_{1}} \log x i}{n} \\
& \text { Sdlog } x=\left\lfloor\left.\frac{\sum_{l=1}^{n}(\log x i-\log \overline{\mathrm{X}})}{n-1}\right|^{2}\right]^{0,5}
\end{aligned}
$$

Dimana:

$$
\begin{array}{ll}
\log \mathrm{X}_{\mathrm{T}} & \text { Logaritma curah hujan } \\
& \text { maksimal untuk } \\
& \text { periode ulang T-tahunan } \\
& = \\
\log \overline{\mathrm{X}} & \text { Logaritma nilai rata-rata } \\
& \text { sampel data curah hujan } \\
\mathrm{Sd} \log x & \text { Logaritma simpangan } \\
& \text { baku (standar deviasi) } \\
& \text { data curah hujan } \\
= & \text { Faktor frekuensi atau } \\
\mathrm{K}_{\mathrm{T}} & \text { faktor probabilitas }
\end{array}
$$

\section{Metode distribusi log normal}

Curah hujan rata-rata pada suatu daerah tertentu dari data stasiun pencatatan curah hujan dapat ditentukan dengan metode Gumbell, Log Pearson Tipe III dan Log Normal (Soewarnom1995).

a. Distribusi Gumbel Tipe I

$$
\mathrm{X}_{\mathrm{T}}=\overline{\mathrm{X}}+\frac{s_{d}}{s_{\pi}}\left(Y_{T}-Y_{n}\right)
$$

b. Distribusi Log Pearson Tipe III

$$
\mathrm{Y}=\overline{\mathrm{Y}}+\mathrm{k} \times \mathrm{S}
$$

c. Distribusi Log Normal

$$
\mathrm{X}_{\mathrm{t}}=\mathrm{X}+\mathrm{Kt} \mathrm{x}
$$

Keterangan :

$\mathrm{X}_{\mathrm{T}} \quad=$ Hujan dalam periode ulang $\mathrm{T}$ tahun (mm)

$\overline{\mathrm{X}} \quad=$ Hujan rerata $(\mathrm{mm})$

$\mathrm{Sd}=$ Standar deviasi

$\mathrm{Y}_{\mathrm{t}} \quad=$ Reduced variate

$\mathrm{Y}_{\mathrm{n}} \quad=$ Harga rerata reduced variate

$\mathrm{S}_{\mathrm{n}} \quad=$ Standar deviasi reduced variate

$\mathrm{Y}=$ Nilai Logaritma dari $\mathrm{X}$ atau $\log \mathrm{X}$

$\mathrm{k}=$ Karakteristik distribusi peluang Log Pearson Tipe III

$\mathrm{S}=$ Deviasi standar nilai $\mathrm{Y}$

\section{Uji kecocokan distribusi frekuensi}

Beragam distribusi yang telah ditampilkan belum tentu semua cocok atau sebaliknya semua bisa cocok. Untuk itu perlu dicari distribusi yang paling cocok melalui analisis goodness of fit dengan menggunakan uji Chi-Square dan uji Smirnov-Kolmogorov (Suripin, 2004).

a. Uji Chi-Square

Uji Chi-Square dimaksudkan untuk menentukan apakah persamaan distribusi yang dipilih dapat mewakili distribusi statistik sampel data yang dianalisis. Parameter $\mathrm{Xn}^{2}$ merupakan variabel acak. Untuk uji Chi-Kuadrat Jika nilai $\mathrm{X}^{2}$ Hitung $<\mathrm{X}^{2} \mathrm{Cr}$ (diterima).

$$
\mathrm{X}_{\mathrm{h}}^{2}=\sum_{\mathrm{i}=1}^{\mathrm{n}} \frac{\left(\mathbf{O}_{\mathrm{i}}^{-}-\mathbf{E}_{\mathrm{i}}\right)^{2}}{\mathbf{E}_{\mathrm{j}}}
$$

Keterangan:

$X h^{2}=$ Parameter Chi-Square terhitung

$\mathrm{G}=$ Jumlah sub kelompok

Oi = Jumlah nilai pengamatan ada sub kelompok i

$\mathrm{Ei}=$ Jumlah nilai teoritis pada sub kelompok i

b. Uji Smirnov-Kolmogorov

Pengujian kecocokan sebaran dengan metode ini dilakukan dengan membandingkan probabilitas untuk tiap variabel dari distribusi empiris dan teoritis didapat perbedaan ( ) tertentu. Perbedaan maksimum yang dihitung 
( maks) dibandingkan dengan perbedaan kritis ( cr) untuk suatu derajat nyata dan banyaknya variat tertentu, maka sebaran sesuai jika ( maks) < ( cr) (Soewarno, 1995):

$$
\mathrm{A}=\frac{P_{\text {maks }}}{P(z)}=\frac{P(x)}{\Delta_{C r}}
$$

\section{Intensitas curah hujan}

Intensitas curah hujan yang dinyatakan dengan (I) menyatakan besarnya curah hujan dalam jangka pendek yang memberikan gambaran derasnya hujan per jam. Perhitungan curah hujan rencana dapat dilakukan dengan menggunakan rumus empiris dari Mononobe sebagai berikut (Suripin, 2004 dalam Fachrizal dan Wesli, 2015):

$$
I=\frac{K Z 4}{t c}+\left[\frac{t c}{t}\right]^{2 / 3}
$$

Dimana:

$$
\begin{aligned}
\mathrm{I} & =\text { Intensitas curah hujan }(\mathrm{mm} / \mathrm{jam}) \\
\mathrm{R}_{24}= & \text { Curah hujan maksimum dalam } 24 \\
& \text { jam }(\mathrm{mm}) \\
\mathrm{t}_{\mathrm{c}} & =\text { Waktu konsentrasi (jam) } \\
\mathrm{t} & =\text { Lamanya curah hujan (jam) }
\end{aligned}
$$

\section{Penentuan waktu konsentrasi}

Waktu konsentrasi adalah waktu yang diperlukan air hujan yang jatuh untuk mengalir dari titik terjauh sampai ke titik outlet (titik kontrol). Salah satu metode untuk memperkirakan waktu konsentrasi adalah dengan rumus yang dikembangkan oleh (Kirpich, 1940 dalam Sriyono, 012) yaitu:

$$
\mathrm{t}_{\mathrm{c}}=0,006628 \mathrm{xL}^{0,77} \mathrm{x} \mathrm{S}^{-0,35}
$$

Dimana:

$$
\begin{aligned}
& \mathrm{t}_{\mathrm{c}} \quad=\text { Waktu konsentrasi (jam) } \\
& \mathrm{L} \quad=\text { Panjang saluran dari hulu sampai } \\
& \text { titik kontrol }(\mathrm{km}) \\
& \mathrm{S}=\text { Kemiringan lahan antara elevasi } \\
& \text { hulu dan hilir } \\
& \mathrm{S}=\frac{\text { Elevasi Hulu }- \text { Elevasi Hili }}{\mathrm{L}}
\end{aligned}
$$

\section{METODE PENELITIAN}

Penelitian ini dilakukan pada wilayah Jalan Gunung Bungkuk kelurahan Tanah Patah. Kelurahan Tanah Patah merupakan kelurahan yang luas wilayahnya mencapai $300 \mathrm{Ha}$. Lokasi penelitian dapat dilihat pada Gambar 1.

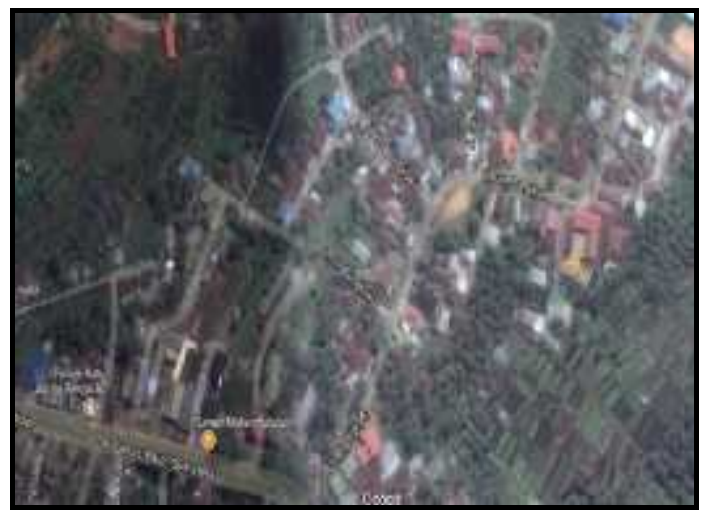

Sumber: Google maps ,2017

Gambar 1. Lokasi Penelitian

\section{Tahapan pelaksanaan penelitian}

Tahapan pelaksanaan pada penelitian yang akan dilakukan sebagai berikut:

1. Pengumpulan data primer dan data sekunder

2. Analisa penyebab terjadinya banjir

3. Analisa hidrologi

Analisa hidrologi ini dimaksudkan untuk mendukung penelitian, khususnya dalam menentukan curah hujan rencana dan karakteristik hidrologi lainnya. Data curah hujan yang di perlukan adalah curah hujan harian dan jumlah hari hujan. Pada kegiatan ini, data yang di digunakan dari BMKG Provinsi Bengkulu. Tahapan analisa hidrologi dalam penelitian ini adalah :

1. Analisa data curah hujan harian maksimal selama periode data 15 tahun dari tahun 2002 sampai 2016 untuk mendapatkan hujan selama 24 jam.

2. Menentukan parameter statistik dari data yang telah diurutkan dari kecil kebesar, yaitu Deviasi standar (Sd), Koefisien kemencengan (Cs), Koefisien Kurtosis $(\mathrm{Ck})$, dan Koefisien variasi $(\mathrm{Cv})$. 
3. Hitung nilai rata-rata

$$
\overline{\mathrm{X}}=\frac{\sum_{\mathrm{j}=1}^{\mathrm{N}} \mathrm{Xi}}{\mathrm{n}}
$$

4. Hitung deviasi standar

$$
\mathrm{Sd}=\sqrt{\frac{\sum_{i=1}^{\mathrm{n}}\left(\mathrm{X}_{\mathrm{f}}-\mathrm{X}\right)}{\mathrm{n}-1}}
$$

5. Hitung koefisien kemencengan

$$
C s=\frac{n \sum_{i}^{2}=\left\{\left(x_{1}\right)-\bar{x}\right]^{2}}{(n-1)(n-2) s d^{5}}
$$

6. Hitung koefisien kurtosis

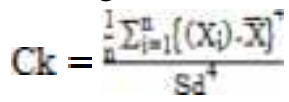

7. Hitung koefisien variasi

$$
\mathrm{Cv}=\frac{\mathrm{Sc}}{\overline{\mathrm{X}}}
$$

8. Analisis curah hujan rencana dicoba dengan menggunakan distribusi, yaitu distribusi Gumbel Tipe I, Log Pearson Tipe III, dan Log Normal. Rumus umum yang digunakan $\mathrm{X}_{\mathrm{t}}=\overline{\mathrm{X}}+\mathrm{Kt} \times \mathrm{S}$.

9. Penentuan waktu konsentrasi hujan Tc dengan rumus Kirpich.

$\mathrm{t}_{\mathrm{c}}=0,06628 \times \mathrm{L}^{0,77} \times \mathrm{S}^{-0,982}$

10. Analisis untuk intensitas curah hujan rencana periode ulang $5,10,20$ dan 50 tahun. Rumus yang digunakan dalam menghitung intensitas hujan adalah rumus Mononobe.

$\mathrm{I}_{\mathrm{t}}=\frac{\mathrm{K}_{24}}{74} \times\left[\frac{24}{\mathrm{t}}\right]^{2 / 5}$

11. Analisis hidraulika
a. Mengetahui titik banjir dari masing- masing saluran.
b. Analisa saluran eksisting drainase.
c. Perencanaan dimensi saluran drainase.

12. Analisis penanganan saluran drainase eksisting

\section{HASIL DAN PEMBAHASAN}

\section{Digitasi lahan perumahan}

Pendigitasian lahan perumahan di google earth ini berfungsi untuk mencocokkan letak peta sesuai letak koordinat dari perumahan tersebut dan sebagai patokan nantinya untuk mengukur luas area dan panjang saluran di autocad. Langkah-langkah dalam pendigitasian lahan ini adalah:

\section{Digitasi}

Tahapan digitasi diwali dengan membuka software google earth. Kemudian klik icon add path. Klik satu demi satu dengan mengelilingi setiap blok perumahan. Isi nama path sesuai blok perumahan.

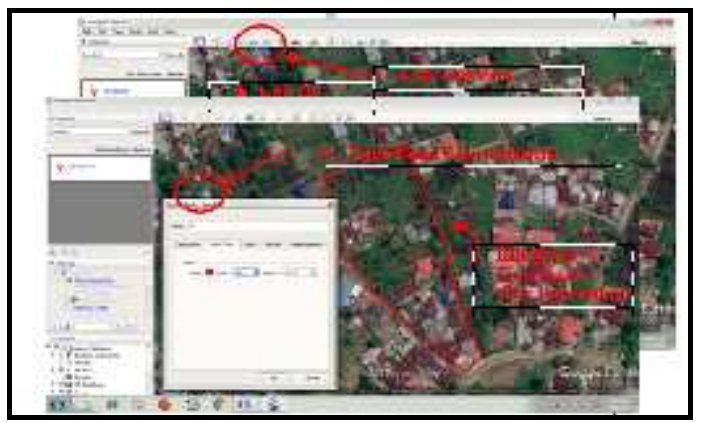

Sumber: Hasil Digitasi Poligon di Google Earth, 2016

Gambar 2. Proses Digitasi Subcatchment

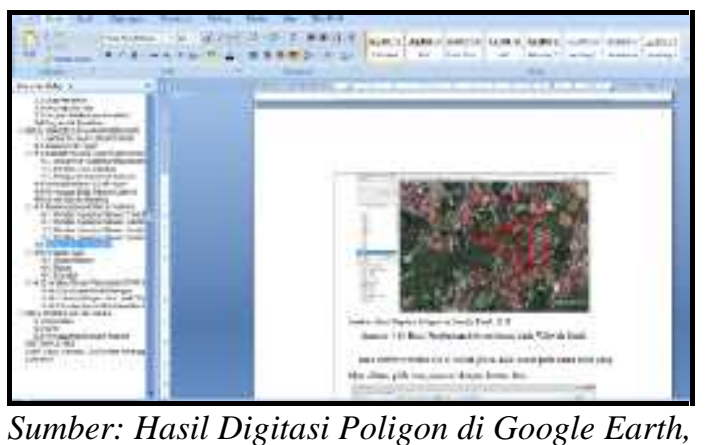
2018

Gambar 3. Hasil Pembagian Subcatchment pada Wilayah Studi

Pada sidebar sebelah kiri di kolom place. Klik kanan pada nama path yang telah dibuat, pilih save place as dengan format.kml.

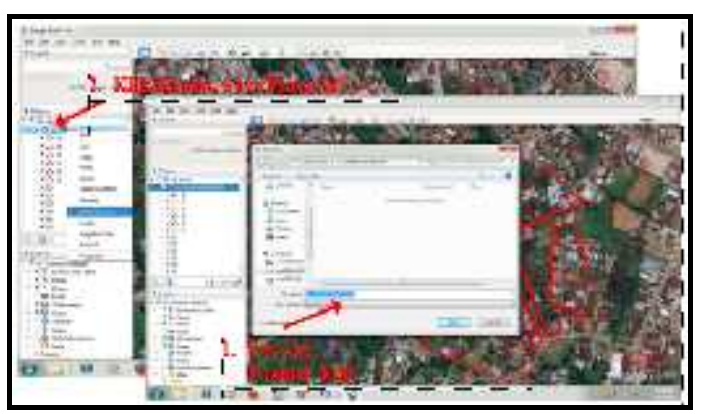

Gambar 4. Penyimpanan Wilayah Studi 
2. Convert file $. \mathrm{kml} \mathrm{ke} . \mathrm{dwg}$

Untuk mengkonversi file .kml ke .dwg yaitu dengan menggunakan Software Global Mapper. Selanjutnya open file .kml yang telah kita buat. Atur tool configuration dengan mengubah projection ke format UTM dan ganti zona wilayahnya dengan zona UTM Sumatera Bagian Selatan yang berada pada -48S. Selanjutnya export Vector/Lidar Format ke .dwg.

\section{Persiapan data}

Persiapan data merupakan langkah awal sebelum pemodelan di software EPA SWMM 5.1. Data tersebut adalah data gabungan dari data primer dan data sekunder. Data-data harus dikumpulkan terlebih dahulu agar nantinya tidak berulang dalam mengedit data.

\section{Subcatchment}

Jl.Gunung Bungkuk ini hampir mencapai 75 $\%$ terdiri dari permukaan yang tidak dapat melewatkan air ke dalam tanah (impervious) yakni berbentuk aspal beton serta lapen pada area-area jalan dan permukaan yang dapat melewatkan air (previous) yang berada pada bagian halaman rumah dan jalan depan rumah. Kawasan perumahan ini terdiri dari 89 subcatchment dan 8 subcatchment dari perumahan tetangga yang dibagi dengan melihat pertimbangan elevasi dan aliran air pada saat terjadinya hujan. Subcatchment tersebut dinamakan S1-S52 dan didalam satu blok perumahan dibagi lagi 2-3 subcatchement. Langkah selanjutnya adalah mencari parameter-parameter untuk melengkapi data subcatchment. Parameter tersebut antara lain:

\section{Area}

Area subcatchment yang digunakan adalah area dari luas tiap blok ditambah dengan jalan lingkungan yang ada. Mencari area dapat menggunakan rumus luasan. Pada penelitian ini untuk mendapatkan luasan dari tiap subcatchment menggunkan software autocad dari file digitasi perumahan di google earth yang telah dibuat sebelumnya. Langkah-langkahnya dengan cara sebagai berikut:

a. Klik pada salah satu subcatchment

b. Klik kanan, pilih "properties"

c. Muncul tabel yang menunjukkan area subcatchment

2. Width

Width adalah lebar dari subcatchment yang berhadapan langsung dengan saluran menuju outlet. Nilai width didapat dengan menggunakan autocad dengan cara yaitu:

a. Klik icon "Aligned" di dalam tab icon linear

b. Tentukan subcatchment yang yang diinginkan

c. Klik dari ujung Inlet dan klik lagi di ujung Outlet yang berada disamping subcatchment

3. \% Slope

$\%$ slope adalah kemiringan dari subcatchment. Pada penelitian ini \% slope pada subcatchment didapat dari software google earth dengan langkahlangkah sebagai berikut:

a. Klik kanan pada salah satu path

b. Klik Show Elevation Profile

4. \% Impervious

\% Impervious adalah luas dari daerah subcatchment yang kedap air, tidak dapat menyerap air, misalnya jalan berasapal, rumah tinggal, perkantoran, pabrik, pertokoan dan ditentukan berdasarkan persentase. Pada penelitian ini persentase dihitung dengan melihat tutupan lahan dari google earth.

\section{N-impervious}

$N$-impervious adalah koefisien angka manning untuk daerah yang kedap air, contoh, pemukiman, jalan raya, dll. Nilai $N$-impervious didapat dari tabel dengan nilai 0,012 . 
6. N-Pervious

$N$-Pervious adalah koefisien angka manning untuk daerah yang tidak kedap air contoh, sawah, kebun, taman dan hutan. Nilai $N$-pervious didapat dari tabel dengan nilai 0,15 .

7. D-Store imperv

D-Store imperv adalah kedalaman depression storage pada daerah yang kedap air. Nilai yang didapat adalah 1,27 $\mathrm{mm}$.

8. D-Store perv

$D$-Store perv adalah kedalaman depression storage pada daerah yang tidak kedap air. Nilai yang didapat adalah $2,54 \mathrm{~mm}$.

9. \% Zero impervious

$\%$ Zero impervious adalah persen daerah impervious yang tidak memiliki depression storage dari perhitungan didapat $71,35 \%$.

\section{Method}

Metode infiltrasi yang digunakan adalah Curve Number. Metode ini mengasumsikan total kapasitas infiltrasi pada tanah yang dapat ditemukan dari tabel Curve Number. Input untuk metode ini adalah nilai curve number dan waktu yang diperlukan untuk tanah jenuh menjadi kering sepenuhnya.

Setelah semua nilai parameter didapat berdasarkan pengukuran dan nilai pada tabel lampiran, maka didapat parameter nilai masukkan untuk karakteristik subcatchment pada SWMM 5.1 dan selanjutnya adalah parameter nilai dari subcatchment yang didapat dari hasil digitasi di google earth dan pengukuran di autocad, dapat dilihat pada Tabel 1.
Tabel 1. Nilai Masukan Karakteristik Subcatchment Pada SWMM 5.1

\begin{tabular}{|c|c|}
\hline $\begin{array}{l}\text { Karakterlstik Subcatchment } \\
\text { N Impen }\end{array}$ & $\begin{array}{l}\text { Nilal } \\
0.012\end{array}$ \\
\hline N-Pan & 0.15 \\
\hline Dstore-incory & 1.27 \\
\hline D.thine-i $j^{3} R v y$ & 2,74 \\
\hline$\therefore$ Zro Impor & 71,35 \\
\hline curve Nambsr & 20 \\
\hline Ds ing Time (lan) & 7 \\
\hline
\end{tabular}

Tabel 2. Luas Subcatchment, Persen Slope, Impervious dan Width

\begin{tabular}{|c|c|c|c|c|c|c|}
\hline & & Aroes Kiste & & & & \\
\hline 1 & sish- & Purumalisu & Arese & 4 & $\%$ & I \\
\hline$\left.\right|^{\text {Eeterangan }}$ & taostemen & (m) & far & sangs & saygure & axup \\
\hline $\begin{array}{l}\left.\right|_{11} \text { :imme } \\
\text { | Iundkuk: }\end{array}$ & s3 & ossovi & 0,3 & 7.7 & P: & 129 \\
\hline 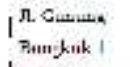 & st ilans $\leqslant$ & 14000 & 24 & $1 . \pi$ & $x$ & 101 \\
\hline 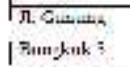 & $\leqslant 3,1, a n \leqslant 4$ & $1>n 00$ & 1) & it. & $x$ & $4{ }^{\circ}$ \\
\hline I Il simatuk: & \$: & 0.000 & 0,0 & 1,: & $\%:$ & $2: 4$ \\
\hline I Iutal & 6 & 110.000 & $\lfloor 1,00$ & & Estu & \\
\hline
\end{tabular}

\section{Node}

Node adalah titik pertemuan dari saluran saluran yang terdiri sebagai satu sistem drainase yang terdiri dari junction dan outfall. Node menjadi tempat pertemuan inlet dan outlet serta masuknya aliran permukaan dari subcathment. Jumlah node pada Jl. Gunung Bungkuk berjumlah 10 junction dan 1 outfall node. Parameter input untuk node junction meliputi:

1. Elevasi saluran didapat dari pengukuran lapangan dengan waterpass.

2. Kedalaman maksimum (nilai ini mengikuti kedalaman saluran).

\section{Conduit}

Conduit adalah saluran atau pipa yang berfungsi memindahkan air dari satu junction node ke junction node yang lain. Penampang saluran dientukan apakah saluran terbuka ataukah tertutup serta lapisan pada saluran tersebut untuk menentukan nilai koefisen kekasarannya. Parameter dalam membuat conduit meliputi: 
1. Bentuk saluran (open atau close channel).

2. Kedalaman maksima 1 (berdasarkan pengukuran penampang).

3. Panjang saluran.

4. Koefisien kekasaran berdasarkan material beton adalah 0,011 .

Analisis dengan pemodelan SWMM 5.1

Menurut Rosmann (2004), SWMM merupakan suatu pemodelan matematika yang digunakan untuk mensimulasikan kuantitas dan kualitas runoff suatu daerah akibat air hujan atau kombinasi dengan sistem air limbah. SWMM 5.1 menggabungkan perhitungan dinamis rainfall-runoff untuk satu kejadian atau simulasi yang berkelanjutan (Huber dan Dickinson, 1998 dalam Ningsih, 2013).

Data hujan diperlukan untuk melihat respon terhadap subcatchment. Infiltrasi menggunakan model Horton's, Green and Ampt's atau Curve Number, waktu konsentrasi yang dihitung berdasarkan teori Kinematic Wave, dan runoff yang diteruskan dengan menggunakan prinsip algoritma non linier. Sementara untuk aliran permukaan dihitung dengan mempertimbangkan tipe penggunaan lahan, topografi, kelembaban tanah, kehilangan infiltrasi pada area previous, dan penahan di permukaan (Chung dkk., 2010 dalam Ningsih 2013).

\section{Pembuatan model jaringan}

Pemodelan jaringan drainase merupakan langkah utama dalam simulasi. Sistem jaringan drainase yang ada di lapangan dimodelkan ke dalam EPA SWMM 5.1 menjadi beberapa bagian subcatchment area. Secara umum dari hasil observasi lapangan diketahui beberapa bentuk ukuran yang dimasukkan ke dalam pemodelan adalah subcatchment area, junction nodes, conduit, dan outfall nodes. Untuk kawasan Jl. Gunung Bungkuk ditambah dengan perumahan sekitar terdiri dari 6 subcatchments, 10 junction nodes, 10 conduits, dan 1 outfall node. Hasil dari pemodelan jaringan output dari SWMM dapat dilihat pada Gambar 5.

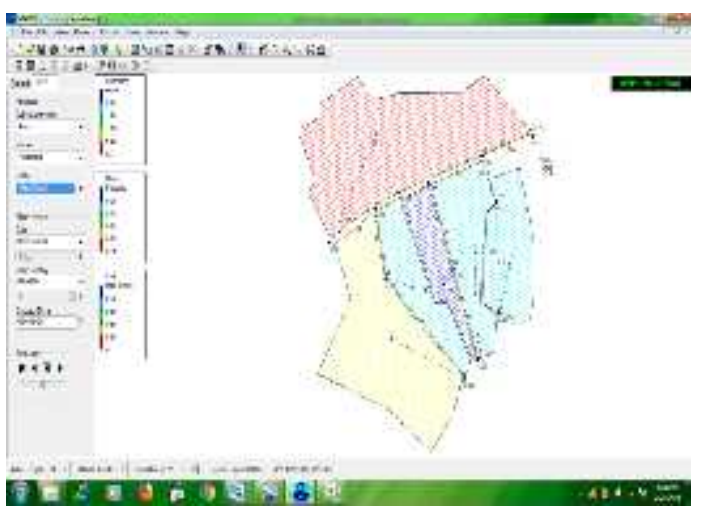

Gambar 5. Pemodelan Jaringan Drainase

\section{Simulasi respon aliran pada time series}

Dalam pemodelan SWMM selanjutnya dilakukan pemodelan simulasi aliran. Simulasi aliran ini dilakukan dengan menggunakan data curah hujan rencana yang telah didapatkan dari hasil analisis hidrologi sebelumnya. Dari curah hujan harian rencana sebesar 646,379 $\mathrm{mm} / \mathrm{hari}$ maka dilakukan simulasi aliran sebagai respon curah hujan terhadap durasi. Pada penelitian ini ditetapkan bahwa lama waktu efektif hujan yang berlangsung selama satu hari berdasarkan kurva IDF Mononobe.

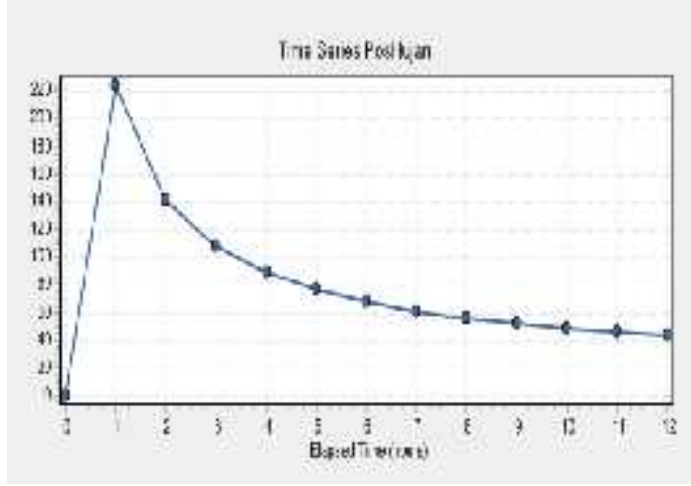

Gambar 6. Time Series Sebaran Hujan Pos Hujan

\section{Simulasi dan analisis kapasitas saluran}

Dari simulasi yang dilakukan didapat hasil kualitas simulasi pada Jl. Gunung Bungkuk yang cukup baik di mana continuity error untuk limpasan permukaan dan penelusuran 
aliran masing-masing sebesar $-0.65 \%$ dan $0.14 \%$. Menurut Rossman (2004) jika kualitas simulasi mencapai angka $10 \%$, maka kualitasnya diragukan.

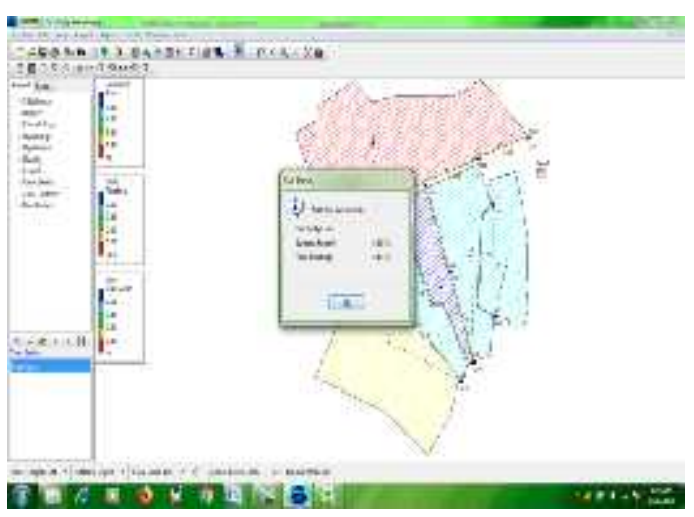

Gambar 7. Hasil Run Status SWMM yang berhasil

Dari total hujan sebesar $638,55 \mathrm{~mm}$ selama hujan efektif 6 jam, respon subcatchment menunjukkan bahwa rata-rata $7,25 \mathrm{~mm}$ persubcatchment yang terinfiltrasi dan sisanya menjadi limpasan sebesar 173,29 mm. Hasil perhitungan limpasan yang terjadi pada setiap subcatchment disajikan pada Tabel 3.

Tabel 3. Hasil perhitungan Infiltasi dan Limpasan SWMM 5.1
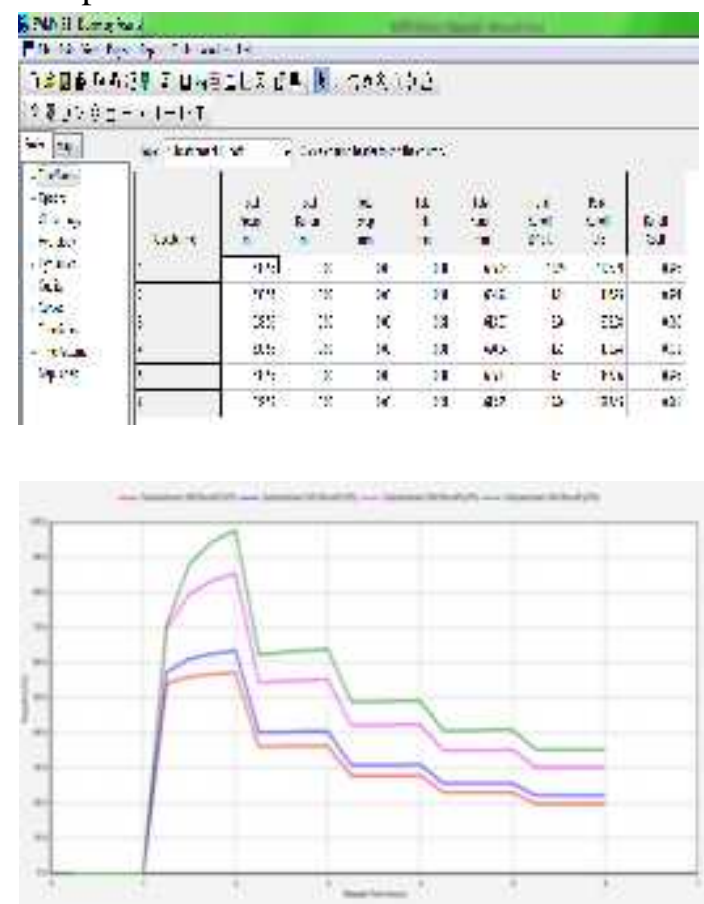

Gambar 8. Besarnya Limpasan terhadap Waktu
Debit limpasan yang mengalir pada tiap-tiap saluran juga berbeda-beda tergantung pada letak saluran, elevasi saluran, kekasaran saluran, dan dimensi saluran. Dari 10 saluran yang terdapat pada permodelan ini, debit aliran maksimum terbesar berada pada saluran C6 sebesar 2459,79 1tr/det. Saluran C6 merupakan saluran terakhir yang berhubungan langsung dengan titik muara saluran. Oleh sebab itu, wajar jika saluran ini memiliki debit aliran maksimum terbesar di antara saluran-saluran yang ada dikarenakan saluran C6 merupakan tempat berkumpulnya limpasan dari seluruh permukaan di Jl. Gunung sedangkan saluran dengan debit aliran paling kecil adalah saluran C10 dengan aliran maksimum sebesar 184,55 1tr/det. Data debit aliran maksimum untuk seluruh saluran ditampilkan pada Tabel 4.

Tabel 4. Hasil Perhitungan Debit Aliran pada Saluran dengan SWMM 5.1

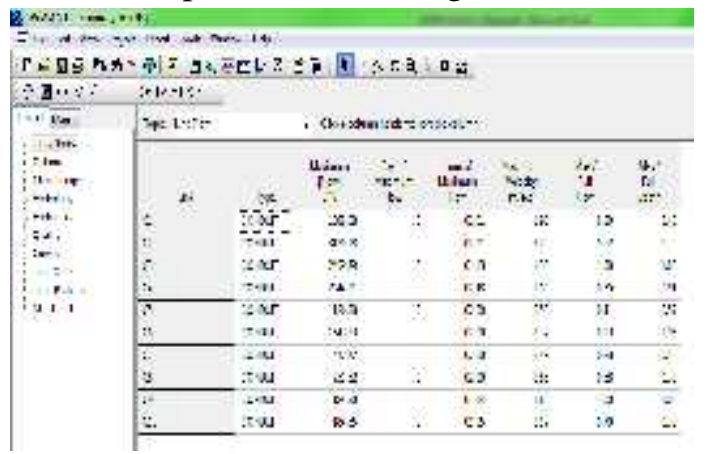

Dari hasil simulasi juga dapat dilihat bahwa terdapat 2 saluran yang tidak dapat menampung limpasan sehingga meluap. Saluran-saluran yang meluap tersebut adalah J3 dan J9. Dalam Gambar 9 saluran yang meluap ditunjukkan oleh garis berwarna merah. Warna merah menunjukkan bahwa aliran pada saluran tersebut melebihi kapasitasnya. Saluran pertama yang meluap adalah saluran C3 yang terletak di antara node J3 dan J4. 


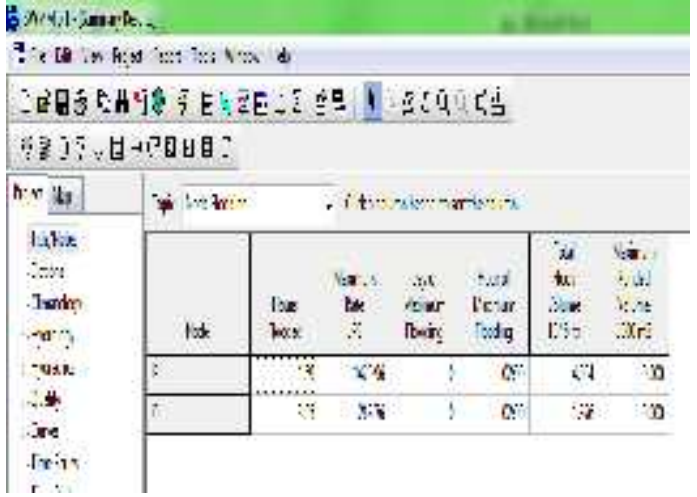

Gambar 9. Hasil Perhitungan saluran yang tidak dapat menampung limpasan

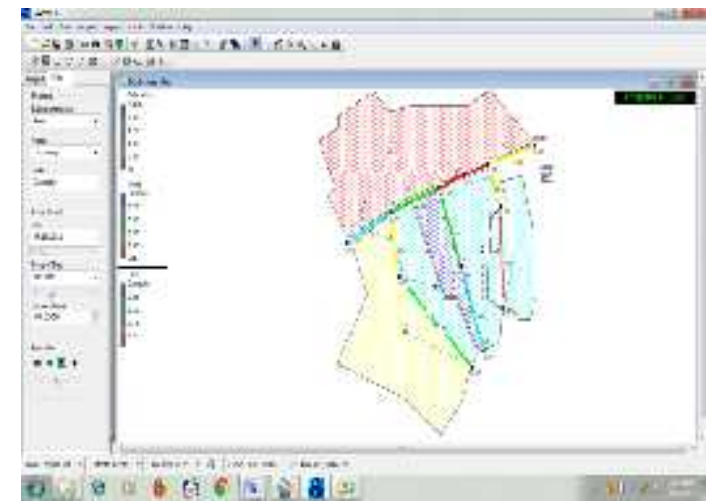

Gambar 10. Saluran Meluap Berwarna Merah

Hasil ketinggian aliran maksimum dimana pada beberapa saluran terjadinya luapan dapat dilihat pada profil aliran yang ditunjukkan pada Gambar 11 dan 12. Dari hasil yang diperoleh, pada Gambar 4.20 dapat dilihat pada jam 01.15 time of day untuk aliran dari node $\mathrm{J} 3$ hingga $\mathrm{J} 9$ terjadinya luapan pada saluran C9 dan C3. Sementara untuk saluran lainnya tidak terjadi luapan karena ketinggian aliran maksimum masih berada di bawah ketinggian saluran. Namun keadaan saluran tidak berada pada posisi yang baik dimana kemiringan saluran hingga menuju outlet cenderung landai sehingga perlu ditambah kemiringannya untuk mempercepat aliran.

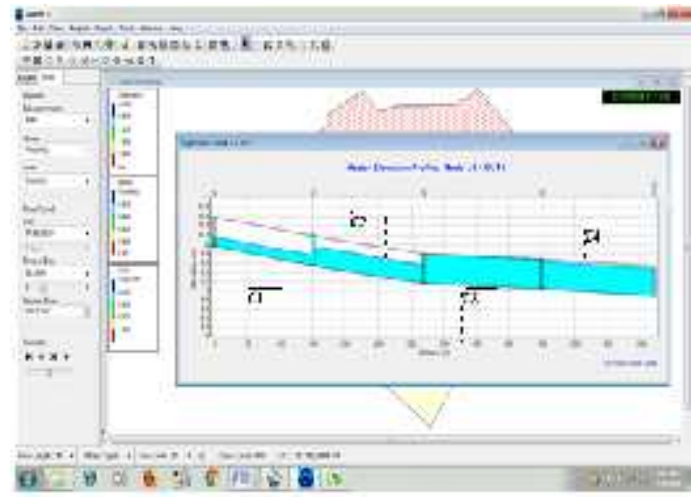

Gambar 11. Aliran Saluran C1, C2, C3, dan C4

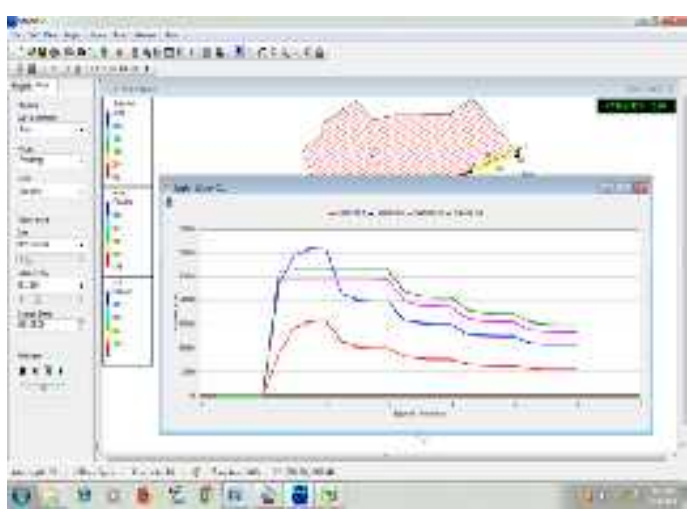

Gambar 12. Debit Aliran Saluran C1, C2, C3, dan C4

\section{KESIMPULAN}

Berdasarkan hasil pada pembahasan maka penulis dapat menarik kesimpulan sebagai berikut:

1. Panjang saluran drainase yang berada di lingkungan Jl. Gunung Bungkuk adalah $1.239 \mathrm{~m}$, dengan rincian saluran primer sepanjang $670 \mathrm{~m}$, saluran sekunder sepanjang $393 \mathrm{~m}$ dan saluran tersier sepanjang $176 \mathrm{~m}$.

2. Dari total hujan sebesar $638,55 \mathrm{~mm}$ selama hujan efektif 6 jam, respon subcatchment menunjukkan bahwa ratarata $7,25 \mathrm{~mm}$ per-subcatchment yang terinfiltrasi dan sisanya menjadi limpasan sebesar 173,29 mm.

3. Pemodelan saluran drainase Jl. Gunung Bungkuk dengan EPA SWMM 5.1 didapat jumlah 6 subcatchments, 10 
juction nodes dan 10 conduits dan 1 outfall node.

\section{DAFTAR PUSTAKA}

Ardiansyah, Amri, dan Besperi, 2017 Analisis Kemampuan Saluran Drainase terhadap Genangan Banjir di Kelurahan Talang Rimbo Baru Kota Curup. Teknik sipil, Universitas Bengkulu.

Fachrizal dan Wesli., 2015. Analisa Kapasitas Saluran Primer terhadap Pengendalian Banjir Studi Kasus Sistem Drainase Kota Langsa, Teras Jurnal Vol.5 No.1 hal.70, Jurusan Teknik Sipil Universitas Malikussaleh, Kota Langsa.

Purbawijaya, I.B., 2011. Manajemen Resiko Penanganan Banjir pada
Sistem Jaringan Drainase di Wilayah Kota Denpasar, Jurnal Ilmiah Teknik Sipil Vol.15.No.1, Jurusan Teknik Sipil Universitas Udayana, Denpasar.

Soewarno, 1995. Hidrologi Aplikasi Metode Statistik untuk Analisa Data Jilid 1, Bandung, Nova.

Sriyono, E., 2012. Analisis Debit Banjir Rancangan Rehabilitas Situ Sidomukti, Jurnal Teknik Vol.2 No.2, Jurusan Teknik Sipil Fakultas Teknik Universitas Janabadra, Yogyakarta.

Tigri, C., 2013. Tinjauan Sistem Dinase di Kelurahan Karame Kecamatan Singkil, Jurnal Statik, Vol.1 No.7, Fakultas Teknik Jurusan Teknik Sipil Universitas Sam Ratulangi Manado.

Wesli, 2008. Drainase Perkotaan, Yogyakarta, Graha Ilmu. 